\title{
Relation between plant average height of (Cremastra appendiculata) and elevations
}

\author{
Bing-Hua Liao ${ }^{1,2, *}$ \\ ${ }^{1}$ The Key Laboratory of Ecological Restoration in Hilly Areas, Forestry Department of Henan Province, Institute of \\ chemistry and environmental engineering, Ping-ding-shan University, Ping-ding-shan City, 467000, China. \\ 2 Institute of life and science, Henan University, Kai-feng City, He-nan Province, 475004, China.
}

Publication history: Received on 17 October 2020; revised on 10 November 2020; accepted on 13 November 2020

Article DOI: https://doi.org/10.30574/gscarr.2020.5.2.0089

\begin{abstract}
(Cremastra appendiculata) of treating lumbago and arthritis not only is a vital medicinal material plant, but also is a widely distributed wide plant species. This plant species is widely distributed elevation from $500 \mathrm{~m}$ to $3100 \mathrm{~m}$ in forest landscapes and vegetation ecosystems in Mei County of China. However, understanding dynamics of average height of this species is difficult along elevation. This research explained that the links between average height of this species and elevation are the significant positive correlation from $500 \mathrm{~m}$ to $1500 \mathrm{~m}(P<0.01)$ as well as the links between average high of this species and elevation are the significant negative correlation from $1500 \mathrm{~m}$ to $3100 \mathrm{~m}(P<0.01)$. This study provides six ecosystem types and a series of areas ecological adaptation for finding medicinal species. Thus, this study has vital theoretical and practical significance for medicinal plant species protection for the better future of human health and ecosystem function (service, structure) at the spatial-temporal-environmental-disturbance scales (STEDS).
\end{abstract}

Keywords: Average Height; Elevation; Correlation; Areas Ecological Adaptation; Medicinal Plant Species.

\section{Introduction}

More and more researches has assessed links between plant average height (biodiversity, biomass, et al.) and elevation from plant average height (biodiversity, biomass, et al.) of medicinal plant perspective(Table 1) ${ }^{1-11}$, for better future of human health and ecosystems ${ }^{6-14}$. However, medicinal species with typical history spanning over 1500 years, and as well as areas ecological adaptation of a lot of average height of species are unknown, cognitive ecological theory of the links between average height of medicinal species and elevation can be unknown at STEDS ${ }^{1-16}$.

Thus, understanding these medical values of medicinal spices, as well as the links between co-dominance abundance dominancy of species pairs of different areas ecological adaptation and elevation is a vital ecological rule along elevation and environmental gradient in the landscapes.

(Cremastra appendiculata) not only is vital medicinal material of treating lumbago and arthritis, but also is widely distributed wide specie in Mei County of China. This specie is belonging to Cremastra genus of Orchidaceae families of Monocotyledoneae in Angiospermae. Understanding average height of this species is unknown along elevation, however ${ }^{20-22}$. Indeed, our research not only explained that there are links between average height of this species and elevation, but also explained that this species is a medicinal plant of treating lumbago and arthritis by better health.

\footnotetext{
${ }^{*}$ Corresponding author: Bing-Hua Liao

The Key Laboratory of Ecological Restoration in Hilly Areas, Forestry Department of Henan Province, Institute of chemistry and environmental engineering, Ping-ding-shan University, Ping-ding-shan City, 467000, China.
} 
Therefore, there are vital rules of the correlations between the average height of plant species (Cremastra appendiculata) and elevation in vegetation landscapes of Mei County of China.

\section{Material and methods}

Table1 Links between medicinal plant structure number (biomass, height) and elevation

\begin{tabular}{|c|c|}
\hline Links between medicinal plant structure number (biomass, height) and elevation & Authors \\
\hline Links between elevation environments and numbers of plant species at STEDS. & Liao, et al., $2010^{1}$. \\
\hline Links between biomass of medicinal herb and elevation in wetland landscape. & Liao, et al., $2011 \mathrm{a}^{2}$. \\
\hline Links between plant functional number and elevation in forest landscape. & Liao, et al., $2011 b^{3}$. \\
\hline Links between plant functional number and elevation in near-natural forests. & Liao, et al., $2014 \mathrm{a}^{4}$. \\
\hline Links between herbs number and disturbance of different elevation in wetland. & Chen, et al., $2019^{5}$. \\
\hline Links between number of medicinal tree species and elevation in forestation. & Liao, et al., 2019a \\
\hline Links between number of medicinal tree trunk volume and elevation at STEDS. & Liao, et al., $2019 b^{7}$. \\
\hline Links between height of medicinal tree and elevation in the natural landscape. & Liao, et al., 2019c 8 . \\
\hline Links between number of tree community crown volume and elevation in forest. & Liao, et al., $2019 \mathrm{~d}^{9}$. \\
\hline Links between number of tree individual specie's crown volume and elevation. & Liao, et al., $2019 \mathrm{e}^{10}$ \\
\hline Links between herbs number and different disturbance of different elevation. & Liao, 2014 b11. \\
\hline
\end{tabular}

\subsection{Typical environmental condition, situation of typical vegetation and methods of research}

Typical area is local in three zones: firstly, evergreen vegetation of north subtropical zone; secondly, evergreen and deciduous coniferous and broad-leaved mixed forest of north subtropical and warm temperate transition; thirdly, deciduous vegetation of warm temperate zone in Earth. Thus, our research area is local in evergreen and deciduous coniferous and broad-leaved mixed forest in north subtropical and warm temperate transition in Mei County of China (Figure 1).

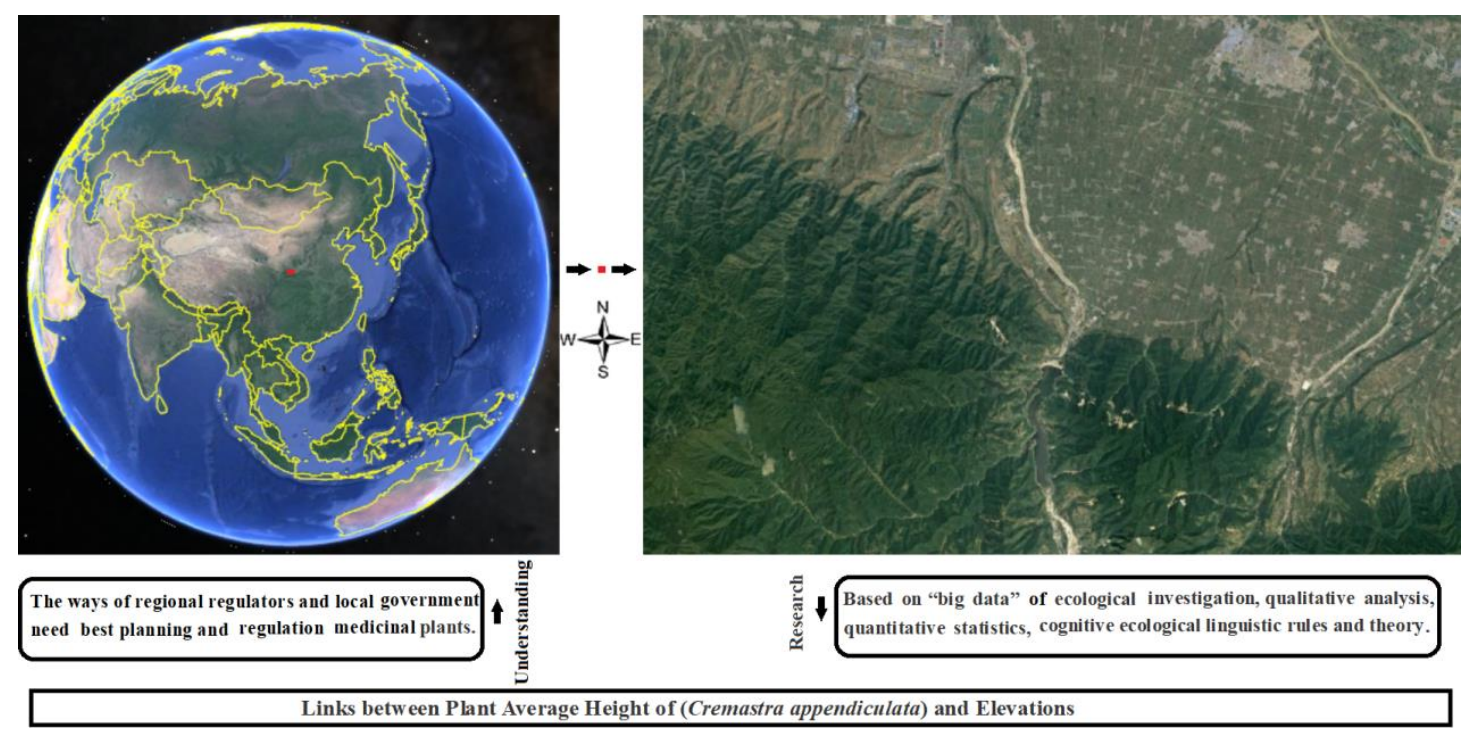


Figure 1 A Digital Cadaster Map and Research Methods of Typical Location of Mei County of China in Earth.

There are the long-time investing the correlations among average height of medicinal plant species and elevation from 2005 to 2019. Investing "big data" included that average height or other index of medicinal plants along environments by previous our researches at STEDS1-12.

Thus, there is a vital rule that the links among average height of (Cremastra appendiculata) and elevation along elevation and environmental gradient by "big data" of ecological investigation, qualitative analysis, quantitative statistics, cognitive ecological linguistic rules and methods ${ }^{5-15}$.

\section{Results and Analysis}

Based on "big data" of plant investigation, this species is a widely distributed wide species along elevation from $500 \mathrm{~m}$ to $3100 \mathrm{~m}$. (Cremastra appendiculata) is a widely distributed along the different elevation from $500 \mathrm{~m}$ to $3100 \mathrm{~m}$ in $\mathrm{Mei}$ County of China. However, understanding the elevation effect on the links between the average height of individual plant species and elevation is very difficult, because different elevation effect on average height of medicinal species ${ }^{17-21}$.

Using the dynamics of "big data" investigation, this research suggested there are four rules:

Firstly, this research suggested that there is not only the increasing of the average height of (Cremastra appendiculata) with increasing of elevation from $500 \mathrm{~m}$ to $1500 \mathrm{~m}$, as well as there are but also decreasing of the average height of (Cremastra appendiculata) with increasing of elevation from $1500 \mathrm{~m}$ to $3100 \mathrm{~m}$ at the STEDS in Mei County of China (Figure 2).

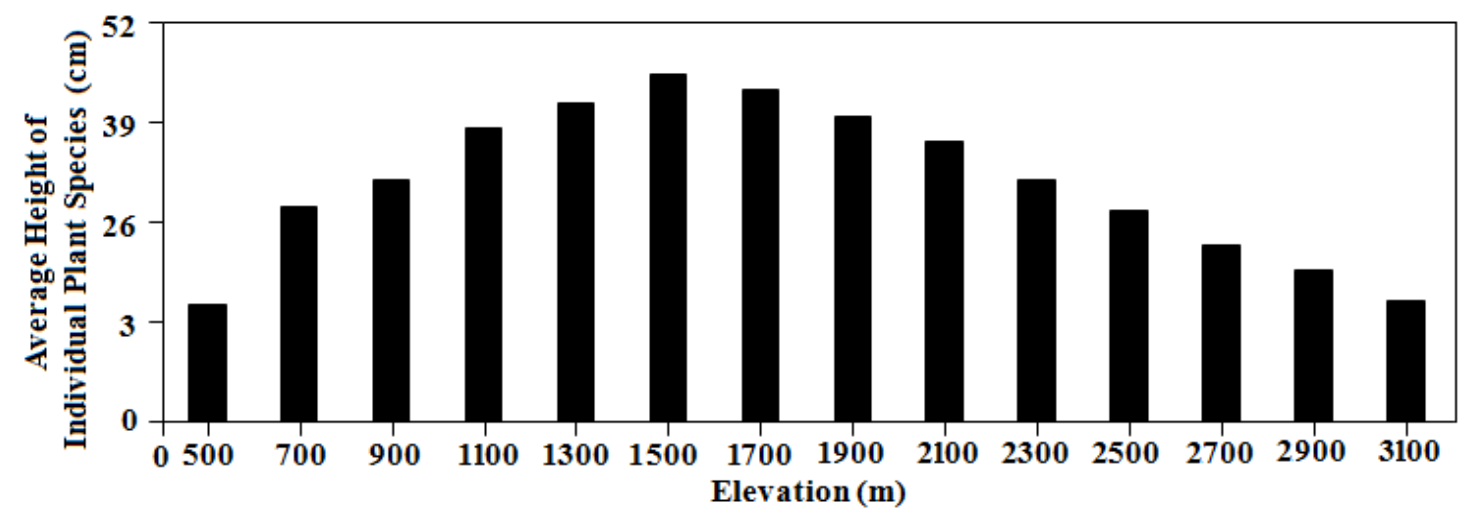

Figure 2 Dynamics of Average Height of Individual Plant Species along Elevation Gradient

Secondly, this study explained that there is the significant positive correlations between average height of (Cremastra appendiculata) and elevation from $500 \mathrm{~m}$ to $1500 \mathrm{~m}(P<0.01)$, as well as there is the significant negative correlations between average height of (Cremastra appendiculata) and elevation from $1500 \mathrm{~m}$ to 3100m in Mei County of China $(P<0.01)$ (Table 2).

Table 2 Correlation between Individual Average Height of this Plant Species and Elevation

\begin{tabular}{|l|l|l|}
\hline Elevation (m) & Elevation From 500m to $\mathbf{1 5 0 0 m}$ & Elevation From $\mathbf{1 5 0 m}$ to $\mathbf{3 1 0 0 m}$ \\
\hline Average Height & $0.990^{* *}$ & $-0.997^{* *}$ \\
\hline
\end{tabular}

Thirdly, this research provides a good areas ecological adaptation of (Cremastra appendiculata) from 500m to 3100 in Mei County in China. Meanwhile, this research proposed that there is not only the better area ecological adaptation of (Cremastra appendiculata) from $1000 \mathrm{~m}$ to $2000 \mathrm{~m}$, there is but also the best areas ecological adaptation of (Cremastra appendiculata) from $1300 \mathrm{~m}$ to $1700 \mathrm{~m}$; because there are results that there are not only dynamics of different air environmental factors, there are but also dynamics of different soil environmental factors from $500 \mathrm{~m}$ to $3100 \mathrm{~m}$ by the dynamics of the links between average height of this species and elevation (Figure 2). 
Fourthly, this research proposed that medicinal plant species (Cremastra appendiculata) is local in six typical ecosystem types (forest ecosystem, mixed ecosystem between forest and grassland, mixed ecosystem between forest and wetland, mixed ecosystem between forest and river, mixed ecosystem between forest and urban, mixed ecosystem between forest and rural settlement) by "big data" of medicinal plant species investing along elevation, because there may be results that there are not only dynamics of the different air environments, there are but also dynamics of the different soil environmental factors from $500 \mathrm{~m}$ to $3100 \mathrm{~m}$ along elevation and environments.

Thus, this research found a series of typical (good, better, best) areas ecological adaptation of (Cremastra appendiculata) of treating lumbago and arthritis along elevation gradient, as well as there is the links between average height of this medical plant species and elevation at STEDS.

\section{Discussion}

Understanding dynamics of medicinal plant species is very difficult1-14,18- 24. This research suggested three conclusions of links average height of (Cremastra appendiculata) and elevation:

1. This research suggested that there is the dynamic increasing of average height of (Cremastra appendiculata) with increasing of elevation from $500 \mathrm{~m}$ to $1500 \mathrm{~m}$, as well as there is the dynamic decreasing of average height of (Cremastra appendiculata) with increasing of elevation gradient from $1500 \mathrm{~m}$ to $3100 \mathrm{~m}$ (Figure 2). There is the significant positive correlation between the average height of (Cremastra appendiculata) and elevation from $500 \mathrm{~m}$ to $1500 \mathrm{~m}(P<0.01)$ as well as there is the significant negative correlation between the average height of (Cremastra appendiculata) and elevation from $1500 \mathrm{~m}$ to $3100 \mathrm{~m}$ along elevation in Mei County of China $(P<0.01)$ (Table 2).

2. This research provides six ecosystem types (forestation, mixed zone between forestation and grassland, mixed zone between forestation and wetland, mixed zone between forestation and river, mixed zone between forest and urban, mixed zone between forestation and rural settlement), as well as there is a series of areas ecological adaptation (a good areas ecological adaptation of Cremastra appendiculata from 500m to 3100, the better area ecological adaptation of Cremastra appendiculata from $1000 \mathrm{~m}$ to $2000 \mathrm{~m}$, the best areas ecological adaptation of Cremastra appendiculata from $1300 \mathrm{~m}$ to $1700 \mathrm{~m}$ ) for finding (Cremastra appendiculata) by environments.

3. (Cremastra appendiculata) not only is a vital medicinal material of treating lumbago and arthritis,but also it is belonging to Cremastra genus of Orchidaceae families of Monocotyledoneae in Angiospermae, as well as it is widely distributed wide specie in Mei County of China.

Therefore, this research has a vital theoretical and practical significance for the reasonable protection of (Cremastra appendiculata) along the different environmental factors of elevation gradient in the different ecosystems, because this plant species not only is an important widely distributed wide medicinal material pant by treating lumbago and arthritis, but also there are three rules by the links between average height of (Cremastra appendiculata) and elevation in Mei County of China. Indeed, better regional regulators and local government need better planning and regulation a lot of medicinal plant management sustainability of ecosystems by the researches on average height (biodiversity, biomass, number, et al.) along elevation and environments with the methods and ways based on "big data" investigation, quantitative statistics, scientific analysis for better future of ecosystems and human health in $t$ global, local, regional landscapes at STEDS $25-41$.

\section{Conclusion}

This article suggests that three conclusions in Mei County of Shan-xi Province of China.

Firstly, human beings are helpless in the face of treating lumbago and arthritis. This article suggested that (Cremastra appendiculata) is a vital medicinal material plant species of treating lumbago and arthritis. And (Cremastra appendiculata) is a widely distributed wide plant species along elevation in Mei County. So, this article provides the best Chinese medicine treatment for human well-being in Chinese medical plant species field of treating lumbago and arthritis.

Secondly, this article provides the distribution elevation and six typical ecosystem types of (Cremastra appendiculata) from 500m to 3100m along different elevation gradient in Mei County. 
Thirdly, this research explained that there are correlations between average height of (Cremastra appendiculata) and elevation are the significant positive correlation from $500 \mathrm{~m}$ to $1500 \mathrm{~m}(\mathrm{P}<0.01)$ as well as correlations between average high of (Cremastra appendiculata) and elevation are the significant negative correlation from $1500 \mathrm{~m}$ to $3100 \mathrm{~m}$ $(\mathrm{P}<0.01)$. So, this article provides a theoretical basis for finding higher medicinal plant materials (Cremastra appendiculata) to resolve treating lumbago and arthritis ways by the "big data" of long-time investigation.

Therefore, this article three conclusion have key scientific and social and ecological value for the better future of human well-being and health and scientific and social and ecological research.

\section{Compliance with ethical standards}

\section{Acknowledgments}

This work was supported by A Grade of Key Disciplines of Environmental Science Foundation, B Grade of Key Disciplines of Mistrials Science of Ping-Ding-shan University in China; Science and Technology Department of He'nan Province Foundation (KJT-17202310242; 092102110165) ; Subprojects by Intergovernmental Platform on Biodiversity and Ecosystem Services (IPBES); and better ideas of researchers of "1st Biotechnology World Congress" in 2011, "2st Biotechnology World Congress" in 2012, “3st Biotechnology World Congress” in 2013 is appreciated.

\section{References}

[1] Liao BH, Wang XH. Plant functional group classifications and a generalized hierarchical framework of plant functional traits, African Journal of Biotechnology, 2010; 9:9208-9213.

[2] Liao BH, Ding SY, Liang GF, et al. Dynamics of plant functional groups composition along environmental gradients in the typical area of Yi-Luo River watershed. African Journal of Biotechnology, 2011a; 10:14485- 14492.

[3] Liao BH, Ding SY, Hu N, et al. Dynamics of environmental gradients on plant functional groups composition on the northern slope of the Fu-Niu Mountain Nature Reserve. African Journal of Biotechnology, 2011b; 10:1893918947.

[4] Liao BH, Liu QF, Lu D, et al. Dynamics of environmental gradients on plant functional groups composition species in near-natural community ecological restoration on the southern slope of the Fu-Niu Mountain Nature Reserve. Journal of Science, 2014a; 4:306-312.

[5] Chen HS, Liao BH, Hang CZ,et al. Research on risk assessment and early warning mechanism of agricultural nonpoint source pollution in Bai-gui Lake watershed by GIS. International Journal of Pharmacognosy and Pharmaceutical Sciences, 2019; 1:25-29.

[6] Liao BH,Liu M.,Huang CZ.,et al.Dynamics of(Sophora japonica)Community's Tree Individual Number along Elevation Gradient in Ye County. International Journal of Pharmacognosy and Pharmaceutical Sciences, 2019a; 1:1-4.

[7] Liao BH, Liu YP, Zuo H, et al. Dynamics of 18 (Sophora japonica) Tree Community's Total Trunk Volume along Elevation Gradient in Ye County. International Journal of Current Advanced Research, 2019c; 8:19063-19066.

[8] Liao BH, Liu YP, Zuo H, et al. Elevation Dynamics of (Sophora japonica) Community's Height in Ye County. International Journal of Research Pharmaceutical and Nano Sciences, 2019b; 8:48 -54.

[9] Liao BH, Liu YP, et al. Dynamics Crown Volume of 18 (Sophora japonica) Tree Communities along Elevation Gradient in Ye County. Open Journal of Ecology, 2019d; 9:209 -215.

[10] Liao BH, Liu YP, Zuo H, et al. Dynamics of 18 (Sophora japonica) Tree Individual Specie's Crown Volume along Elevation Gradient in Ye County. International Journal of Research Pharmaceutical and Nano Sciences, 2019e; 8:62-68.

[11] Liao BH. A new model of dynamic of plant diversity in changing farmlands, implications for the management of plant biodiversity along differential environmental gradient in the spring. African Journal of Environmental Science and Technology, 2014b; 8:171- 177.

[12] Zhu DM, Liao BH. A dynamical system of human cognitive linguistic theory in learning and teaching of the typical university in Henan Province. International Journal of Pharmacy \& Therapeutics, 2015; 6:4-6. 
[13] Yang Y, Sun M, et al. Germplasm resources and genetic breeding of Paeonia: a systematic review. Horticulture Research, 2020; 7:1-19.

[14] Jin D, Dai KP, et al. Secondary Metabolites Profiled in Cannabis Inflorescences, Leaves, Stem Barks, and Roots for Medicinal Purposes. Scientific Reports, 2020; 10:1-14.

[15] Kozuharova E, Matkowski A, et al. Amorpha fruticosa - A Noxious Invasive Alien Plant in Europe or a Medicinal Plant against Metabolic Disease? Front Pharmacol. 2017; 8:333.

[16] Giovannini P, Howes MJ, Edwards SE. Medicinal plants used in the traditional management of diabetes and its sequelae in Central America: A review. J Ethnopharmacol. 2016; 184:58-71.

[17] Szopa A, Klimek-Szczykutowicz M, Kokotkiewicz A, et al. Phenolic acid and flavonoid production in agar, agitated and bioreactor-grown microshoot cultures of Schisandra chinensis cv. Sadova No.1 - a valuable medicinal plant. J Biotechnol. 2019; 305:61- 70.

[18] Mesfin F, Demissew S, Teklehaymanot T. An ethnobotanical study of medicinal plants in Wonago Woreda, SNNPR, Ethiopia. J Ethnobiol Ethnomed. 2009; 5:28.

[19] Elkins AC, Deseo MA, Rochfort S, et al.Development of a validated method for the qualitative and quantitative analysis of cannabinoids in plant biomass and medicinal cannabis resin extracts obtained by super-critical fluid extraction. J Chromatogr B Analyt Technol Biomed Life Sci. 2019; 109:76-83.

[20] Baque MA, Moh SH, Lee EJ, et al. Production of biomass and useful compounds from adventitious roots of highvalue added medicinal plants using bioreactor. Biotechnol Adv. 2012; 30:1255-1267.

[21] Saeed S, Ali H, Khan T, et al. Impacts of methyl jasmonate and phenyl acetic acid on biomass accumulation and antioxidant potential in adventitious roots of Ajuga bracteosa Wall ex Benth., a high valued endangered medicinal plant. Physiol Mol Biol Plants. 2017; 23:229- 237.

[22] Prasad R, Kamal S, Sharma PK, et al.Root endophyte Piriformospora indica DSM 11827 alters plant morphology, enhances biomass and antioxidant activity of medicinal plant Bacopa monniera. J Basic Microbiol. 2013; 53:10161024.

[23] Fuentes P, Zhou F, Erban A, et al.A new synthetic biology approach allows transfer of an entire metabolic pathway from a medicinal plant to a biomass crop. Elife. 2016; 5:e1360-1364.

[24] Rukh G, Ahmad N, et al. Photodependent somatic embryogenesis from non-embryogenic calli and its polyphenolics content in high-valued medicinal plant of Ajuga bracteosa. J Photochem Photobiol B. 2019; 190:5965.

[25] Das A, Kamal S, Shakil NA, et al. The root endophyte fungus Piriformospora indica leads to early flowering, higher biomass and altered secondary metabolites of the medicinal plant, Coleus forskohlii. Plant Signal Behav. 2012; 7:103-112.

[26] Schafhauser T, Jahn L, Kirchner N, et al. Antitumor astins originate from the fungal endophyte Cyanodermella asteris living within the medicinal plant Aster tataricus. Proc Natl Acad Sci USA. 2019; 116:26909-26917.

[27] Singh SP, Gaur R. Evaluation of antagonistic and plant growth promoting activities of chitinolytic endophytic actinomycetes associated with medicinal plants against Sclerotium rolfsii in chickpea. J Appl Microbiol. 2016; 121:506-518.

[28] Das K, Dang R, Shivananda TN, Sur P. Interaction between phosphorus and zinc on the biomass yield and yield attributes of the medicinal plant stevia (Stevia rebaudiana). Scientific World Journal, 2005; 5:390-395.

[29] Zubek S, Mielcarek S, Turnau K. Hypericin and pseudohypericin concentrations of a valuable medicinal plant Hypericum perforatum L. are enhanced by arbuscular mycorrhizal fungi. Mycorrhiza, 2012; 22:149-156.

[30] Takshak S, Agrawal SB. Defence strategies adopted by the medicinal plant Coleus forskohlii against supplemental ultraviolet-B radiation: Augmentation of secondary metabolites and antioxidants. Plant Physiol Biochem, 2015; 97:124-138.

[31] Larsen HO. Commercial medicinal plant extraction in the hills of Nepal: local management system and ecological sustainability, Environ Manage. 2002; 29:88-101.

[32] Bojić M, Maleš Ž, Antolić A, et al. Antithrombotic activity of flavonoids and polyphenols rich plant species. Acta Pharm. 2019; 69:483-495. 
[33] Maleš Ž, Drvar DL, et al. Application of medicinal plants in several dermatovenerological entities. Acta Pharm. 2019; 69:525-531.

[34] Wyk BEV. A review of commercially important African medicinal plants. J Ethnopharmacol. 2015; 176:118-134.

[35] Song H, Payne S, et al. Spatiotemporal modulation of biodiversity in a synthetic chemical- mediated ecosystem. Nature Chemical Biology, 2009; 5:929-935.

[36] Opgenoorth L, Hotes S,Mooney H. IPEPS: Biodiversity panel should play by rules. Nature, 2014; $506: 159$.

[37] Ali H, Khan MA, Kayani WK, et al. Production of biomass and medicinal metabolites through adventitious roots in Ajuga bracteosa under different spectral lights. J Photochem Photobiol B. 2019; 193:109-117.

[38] Volkov I, Banavar JR, et al. The stability of forest biodiversity. Nature, 2004; 427: 696-697.

[39] Catzeflis FM. Mega mining project in French Guiana threatens Amazonian biodiversity. Nature, $2018 ; 561: 464$.

[40] Oehri J, Schmid B, et al. Terrestrial land-cover type richness is positively linked to landscape level functioning. Nature Communications, 2020; 11:1-10.

[41] Liao, Mace GM, Ekins P. Limits to agricultural land for retaining acceptable levels of local biodiversity. Nature Sustainability, 2019; 2: 491-498. 